\title{
Ketamine enhances Phase I and Phase II neuromuscular block of succinylcholine
}

Shen Kou Tsai MD, Chingmuh Lee MD, Barry Tran MD
Whether ketamine interacts with succinylcholine has been controversial. Bovill et al. ${ }^{1}$ observed that ketamine prolonged the action of succinylcholine in man. Bogdan, Glisson and El-Etr ${ }^{2}$ reported that ketamine enhanced the action of depolarizing neuromuscular relaxants in rabbits. By contrast, Johnston, Miller and Way ${ }^{3}$ observed that ketamine had no effect on the dose-response relationship of succinylcholine in man under halothane anaesthesia. None of these previous studies took into consideration the Phase I versus Phase II neuromuscular effect of succinylcholine. Neither Bovill et al. ${ }^{1}$ nor Johnston et al. ${ }^{3}$ measured the recovery index. Furthermore, the effect of succinylcholine in the study of Johnston et al. ${ }^{3}$ might have been obscured by variability of the data. Although not reaching statistical significance, their data showed that the $\mathrm{ED}_{50}$ of succinylcholine was reduced from $5.1 \mathrm{mg} \cdot \mathrm{m}^{-2}$ (body surface area) to $4.1 \mathrm{mg} \cdot \mathrm{m}^{-2}$ by 75 $\mathrm{mg} \cdot \mathrm{m}^{-2}$ of ketamine. Their dose-response curves of succinylcholine showed a consistent shift in the direction of potentiation by ketamine. We therefore undertook a study to elucidate the actions of ketamine on the Phase I and Phase II neuromuscular blocking effect of succinylcholine.

\section{Methods}

The study was approved by the Institutional Review Board. Seven adult male monkeys (Macaca cyclopis) weighing $5-6 \mathrm{~kg}$ were first anaesthetized with methohexitone $10-15 \mathrm{mg} \cdot \mathrm{kg}^{-1}$ intramuscularly. Two intravenous infusion lines were inserted, one in each lower limb. Dextrose five per cent in water was infused IV at 5 $\mathrm{ml} \cdot \mathrm{kg}^{-1} \cdot \mathbf{h r}^{-1}$. Ketamine and succinylcholine were given through separate IV lines. The trachea was intubated without the use of muscle relaxants and anaesthesia was maintained with halothane $0.5-1$ per cent in oxygen. Excessive stimulation was avoided so that a deep level of anaesthesia would not be required. The end-tidal $\mathrm{CO}_{2}$ and halothane concentrations were monitored with a Datex Normocap $\mathrm{CO}_{2}$ monitor and a Datex anaesthetic gas monitor. Ventilation was controlled with a Harvard Apparatus ${ }^{6}$ respiration pump to keep end-tidal $\mathrm{CO}_{2}$ at $30-40 \mathrm{mmHg}$. Oesophageal temperature was maintained 
at $35-37^{\circ} \mathrm{C}$ with a heating lamp and a thermoblanket. An arterial catheter was placed in the anterior tibial artery for blood pressure recording and blood gas determination. Arterial blood $\mathrm{pH}$ was $7.30-7.40$.

The ulnar nerve was stimulated at the wrist with supramaximal electric pulses of $0.2 \mathrm{msec}$ duration derived from a Grass S88 stimulator via a Grass SIU5 stimulus isolation unit. Single twitches were elicited at $0.1 \mathrm{~Hz}$. Periodically, trains of four twitches were elicited at $2 \mathrm{~Hz}$ to detect changing phase of neuromuscular block by the train-of-four fade. ${ }^{4}$ The force of thumb adduction was measured by a Grass FT-03 force transducer. Electrocardiogram, arterial blood pressure, and thumb twitch were recorded simultaneously on a 4-channel Grass Polygraph recorder.

The study involved three steps, including a total of 19 experiments on seven monkeys. Each monkey was allowed an interval of at least one week between experiments. Each time a stable baseline twitch response was recorded for 30 minutes before the experiment began. In step 1 (ketamine control, $\mathrm{n}=5$ ), ketamine was injected IV at hourly intervals at a progressively increasing incremental dosage of 2,5 , and $10 \mathrm{mg} \cdot \mathrm{kg}^{-1}$ to assess its neuromuscular effect in the absence of succinylcholine. The monkeys were allowed to recover. In step 2 (succinylcholine Phase I with ketamine, $n=7$ ), each monkey received $2 \mathrm{mg} \cdot \mathrm{kg}^{-1}$ of ketamine IV followed by determination of the dose-response curve of succinylcholine beginning five minutes later. Each dose of succinylcholine was increasingly larger than the preceding dose, and was not injected until the twitch had recovered from the preceding dose and had remained at baseline value for at least twice the duration of block of the preceding dose. The magnitude of neuromuscular block was converted from percent values to probit units, and plotted against the $\log$ units of dose in $\mathrm{mg} \cdot \mathrm{kg}^{-1}$ for determination of the dose-response curve by a computer. These conversions facilitate linear regression of the dose-response relationship by converting a sigmoid curve to a straight line. ${ }^{5}$ The $\mathrm{ED}_{25}, \mathrm{ED}_{50}, \mathrm{ED}_{75}$ and $\mathrm{ED}_{90}$ of the seven monkeys were thereby determined, as were their $25-75$ per cent recov. ery indices. The monkeys were allowed to recover. In step 3 (succinylcholine Phase I without ketamine, and succinylcholine Phase II + ketamine, $n=7$ ), the same seven monkeys had their dose-response curves of succinylcholine determined exactly as in step 2, except without the ketamine pre-treatment. Following this, succinylcholine was infused intravenously to keep the twitch depressed by 50 per cent ( \pm 5 per cent). When the train-of-four ratio had diminished from near unity to values below 0.4 during continuous infusion of succinylcholine, the nature of neuromuscular block was considered to have changed from Phase I block to Phase II. ${ }^{4}$ After the block had been in Phase II block for 15 minutes with a steady infusion rate of succinylcholine, ketamine in incremental doses of 2,3 and $5 \mathrm{mg} \cdot \mathrm{kg}^{-1}$ was injected - each dose at the full onset of neuromuscular effect of the preceding dose. The cumulative total doses were 2,5 and $10 \mathrm{mg} \cdot \mathrm{kg}^{-1}$. The neuromuscular effect of ketamine was measured by diminution of twitch beyond what was maintained by succinylcholine infusion. Thirty minutes after the injection of the last dose of ketamine, succinylcholine infusion was terminated. On spontaneous recovery of the twitch to baseline, monkeys were allowed to recover from anaesthesia.

Dita are presented as mean \pm SEM. Neuromuscular effect of ketamine was assessed by comparing succinylcholine-induced neuromuscular block with ketamine versus that without ketamine, $\mathrm{P}<0.05$ by Student's paired $\mathrm{t}$ test being considered statistically significant.

\section{Results}

Ketamine at all doses had no consistent effect on the thumb twitch in the absence of succinylcholine. One of the five monkeys had a slight increase in twitch tension. Overall, the thumb twitch was depressed by $3 \pm 1.2$ per cent after the $10 \mathrm{mg} \cdot \mathrm{kg}^{-1}$ dose, not statistically significant from baseline. Table I shows the effect of ketamine 2 $\mathrm{mg} \cdot \mathrm{kg}^{-1}$ pre-treatment on the neuromuscular potency of succinylcholine. The data showed a parallel shift of the two log-probit regression lines. The $25-75$ per cent recovery index of succinylcholine was $5.3 \pm 0.1 \mathrm{~min}$ with ketamine, significantly longer than $4.0 \pm 0.4 \mathrm{~min}$ without ketamine $(\mathrm{P}<0.01)$. During the above experiments (steps 1,2 ), the neuromuscular block of succinylcholine was verified to be in Phase I by a train-of-four ratio of greater than 0.7 at all times. In step 3 experiment, the infusion rate of succinylcholine at the time Phase II block was deemed to have been established was $0.12 \pm 0.08$ $\mathrm{mg} \cdot \mathrm{kg}^{-1} \cdot \mathrm{min}^{-1}$. At that point, the monkeys had received a total of $6.5 \pm 0.5 \mathrm{mg} \cdot \mathrm{kg}^{-1}$ of succinylcholine. The train-of-four ratio was $0.3 \pm 0.05$ for $48 \pm 3$ per cent block of the first twitch. Ketamine invariably depressed the twitch further in a dose-dependent manner (Table II). The onset time of ketamine potentiation (injection of ketamine to maximal effect of ketamine on the (witch) was $5.2 \pm 0.6,3.6 \pm 1.1$, and $4.2 \pm 0.9 \mathrm{~min}(P>0.05$ among them) for 2,5 , and $10 \mathrm{mg} \cdot \mathrm{k}^{-1}$ cumulative total dose of ketamine, respectively. The duration of neuromuscular action of ketamine was not measured because the underlying Phase II neuromuscular block of succinylcholine was known to accumulate over time. Upon termination of succinylcholine infusion, the twitch was observed to recover from the combined ketamine-succinylcholine (Phase II) neuromuscular block to $95-100$ per cent of baseline in $22-62$ minutes. 
TABLE I Effect of ketamine $2 \mathrm{mg} \cdot \mathrm{kg}^{-1}$ pretreatment on the potency of succinylcholine in Phase I neuromuscular block (EDs in $\mathrm{mg} \cdot \mathrm{kg}^{-1}$ )

\begin{tabular}{lrrrr}
\hline & \multicolumn{1}{c}{$E D_{25}$} & \multicolumn{1}{c}{$E D_{s o}$} & \multicolumn{1}{c}{$E D_{75}$} & \multicolumn{1}{c}{$E D_{90}$} \\
\hline Without ketamine & 0.30 & 0.46 & 0.68 & 0.99 \\
& \pm 0.05 & \pm 0.07 & \pm 0.09 & \pm 0.13 \\
With ketamine & 0.21 & 0.33 & 0.51 & 0.74 \\
& \pm 0.04 & \pm 0.06 & \pm 0.09 & \pm 0.13 \\
\hline
\end{tabular}

$\mathrm{P}<0.01$, all comparisons with ketamine ws without ketamine.

TABLE II Effect of ketamine on a preestablished Phase II neuromuscular block maintained at nearly 50 per cent by continuous infusion of succinylcholine

\begin{tabular}{lllll}
\hline $\begin{array}{l}\text { Dose of ketamine } \\
\left(\mathrm{mg} \cdot \mathrm{kg}^{-1}\right)\end{array}$ & 0 & 2 & 5 & 10 \\
\hline \% Block of twitch & 48.0 & 71.0 & 83.0 & 94.0 \\
& \pm 3.0 & \pm 1.5 & \pm 2.0 & \pm 2.3 \\
$\mathrm{P}$ & & $<0.01$ & $<0.01$ & $<0.01$ \\
\hline
\end{tabular}

\section{Discussion}

Ketamine potentiates succinylcholine in the monkey during both the Phase 1 and the Phase II neuromuscular block of succinylcholine. It also prolongs the $25-75$ per cent recovery index of succinylcholine in Phase 1 . We are not aware of other studies of ketamine-succinylcholine interaction in Phase II block. Bovill et al. ${ }^{1}$ and Johnston et al. ${ }^{3}$ studied the effect of $50 \mathrm{mg}$ and $2.5-7.5 \mathrm{mg} \cdot \mathrm{m}^{-2}$ of succinylcholine, respectively. In patients with normal plasma cholinesterase, Phase I neuromuscular block prevails at these doses. ${ }^{6-9}$ Bogdan et al. observed that ketamine in rabbits enhanced the action of succinylcholine. ${ }^{2}$ It was probably also the Phase I effect of succinylcholine that they were observing, as one of us (CL) has always failed to establish in the rabbit or the cat a clear-cut Phase II neuromuscular block with succinylcholine. In our primate model, the enhancement of the Phase II neuromuscular block of succinylcholine by ketamine is conspicuous. As a matter of fact, ketamine potentiates succinylcholine in Phase II more than it potentiates vecuronium, ${ }^{10}$ pancuronium, ${ }^{11}$ atracurium, and d-tubocurarine under identical experimental conditions (Tsai and Lee, unpublished observations). We could not exactly determine the total duration of ketamine enhancement of Phase II neuromuscular block because ketamine is long-acting and succinylcholine-induced neuromuscular block typically drifts and accumulates in Phase II. ${ }^{4,6-9}$ Even a two per cent error every ten minutes would invalidate the twitch data one hour later.

In a manner similar to our study, Johnston et al. ${ }^{13}$ compared the dose-response curve of the halothaneketamine group of patients with the halothane group.
They observed no statistically significant potentiation of succinylcholine by ketamine. However, their data did show deviation from parallelism in the two doseresponse curves of succinylcholine. Both their study and ours obtained objective measurement of neuromuscular response and controlled respiratory gases and core temperature. Their ketamine dose of $75 \mathrm{mg} \cdot \mathrm{m}^{-2}$ approximates our dose of $2 \mathrm{mg} \cdot \mathrm{kg}^{-1}$. Close scrutiny of their data does reveal a strong tendency for ketamine to enhance the neuromuscular potency of succinylcholine. Their $\mathrm{ED}_{50}$ of succinylcholine was $4.1 \mathrm{mg} \cdot \mathrm{m}^{-2}$ with ketamine, versus $5.1 \mathrm{mg} \cdot \mathrm{m}^{-2}$ without ketamine, respectively. Extrapolation of their dose-response curve indicates that succinylcholine $2.5 \mathrm{mg} \cdot \mathrm{m}^{-2}$ would have no neuromuscular effect in the "halothane alone" group. The same dose of succinylcholine did produce a $27.6 \pm 9.5$ per cent block in their halothane-ketamine group. Individual variability must have been smaller in our study because our monkeys are of the same species and sex, and of similar size and age. Individual variability and use of historical control might have obscured the neuromuscular effect of ketamine in their clinical succinylcholine study.

Our results are compatible with those of Bovill et al., who observed in humans that ketamine increased by $30-40$ per cent the duration of apnoea following $50 \mathrm{mg}$ of succinylcholine. Johnston et al. ${ }^{3}$ criticized that obervation and argued that the return of spontaneous respiration in the absence of precise control of respiratory gases could at best be approximations of neuromuscular functions. However, Bovill et al. compared ketamine with thiopentone and methohexitone in their study of succinylcholine apnoea. If any, Bovill $e t$ al. might have underestimated the effect of ketamine on succinylcholine apnoea because ketamine does not depress respiration as much as the barbiturates do.

Use of the monkey in our study deserves comments. Determination of a dose-response curve of succinylcholine by repeated injection may cause bradycardia and sinus arrest. ${ }^{12}$ Establishment of Phase II block may risk protracted paralysis. ${ }^{4}$ Bolus intravenous injection of ketamine on top of halothane anaesthesia may result in unnecessarily profound anaesthesia and cardiovascular depression. We did not observe these problems in the monkeys except for a slight cardiovascular depression, with transient depression of the blood pressure and the heart rate by approximately ten per cent. Nevertheless, we chose to avoid human subjects for this study. For clinical relevancy, we had preliminarily observed that the $\mathrm{ED}_{50}$ of the macaca cyclopis monkey were: vecuronium, ${ }_{t}^{10}$ $0.01 \mathrm{mg} \cdot \mathrm{kg}^{-1}$; pancuronium, ${ }^{11} 0.012 \mathrm{mg} \cdot \mathrm{kg}^{-1}$; atracurium, $0.1 \mathrm{mg} \cdot \mathrm{kg}^{-1}$; and d-tubocurarine, $0.17 \mathrm{mg} \cdot \mathrm{kg}^{-1}$ (Tsai and Lee, unpublished observations). These data and the $\mathrm{ED}_{50}$ of succinylcholine observed herein put this 
species very close to the buman in neuromuscular pharmacological profile as do the data on occurrence and doserequirement of Phase II block. ${ }^{4,6-9}$ This primate model of neuromuscular pharmacology therefore bears superior clinical relevance. A recent study shows that the pig may be a suitable alternative. ${ }^{13}$ However, occurrence of Phase II block in the pig has not been established. All other animal models have more drawbacks.

Potentiation of succinylcholine by ketamine may have clinical implications. In Phase I, the same 30-40 per cent increase in potency and duration of action of succinylcholine was observed by Bovill et al. clinically. ${ }^{1}$ However, it probably will be unnoticed in daily anaesthesia practice except on rare occasions when premature withdrawal of respiratory support by a few minutes may result in transient hypoventilation. In Phase II, the interaction may result in respiratory failure of significant duration. Phase II block occurs after prolonged administration of succinylcholine during surgery or in the intensive care unit, and may follow the first "normal" dose of succinylcholine in patients with atypical or low plasma cholinesterases. ${ }^{14}$

In summary, ketamine potentiates succinylcholineinduced neuromuscular block in the primate. The literature contains conflicting reports of the effect of ketamine on the Phase I neuromuscular block of succinylcholine. These controversies can be reconciled in light of our new observations. The present study adds that ketamine also potentiates the Phase II neuromuscular block of succinylcholine.

\section{References}

1 Bovill JG, Coppell DL, Dundee JW, Moore J. Current status of ketamine anaesthesia. Lancet 1971; 19: 1285-8.

2 Bogdan LG, Glisson SN, El-Etr AA. The effect of ketamine upon depolarizing and nondepolarizing neuromuscular blockade in rabbit. Naunyn-Schmiedebergs Arch Phannacol 1974; 285: 223-31.

3 Johnston RR, Miller RD, Way WL. The interaction of ketamine with d-tubocurarine, pancuronium and succinylcholine in man. Anesth Analg 1974; 53: 496-501.

4 Lee C, Katz RL. Neuromuscular pharmacology, a clinical update and commentary. Br J Anaesth 1980; 52: 173-88.

5 Donlon JV, Ali HH, Savarese JJ. A new approach to the study of four non-depolarizing relaxants in man. Anesth Analg 1974; 53: 934-9.

6 Ramsey FM, Lebowitz PW, Savarese JJ, et al. Clinical characteristics of long-term succinylcholine neuromuscular blockade during balanced anesthesia. Anesth Analg 1980; 59: 110-6.

7 Lee C. Succinylcholine neuromuscular block recxamined. Anesth Analg 1980; 59: 663-4.

8 Donati $F$, Bevan $D R$. Long-term succinylcholine infusion during isoflurane anesthesia. Anesthesiology 1983; 58: 6-10.

9 Goudsouzian NG, Liu LMP. The neuromuscular response of infants to a continuous infusion of succinylcholine. Anesthesiology 1984; 60: 97-101.

10 Tsai SK, Mok MS, Lee C. Tang GJ. Ketamine enhanced vecuronjum-induced neuromuscular block. Anesthesiology 1986; 66: \$179.

11 Tsai $S K$, Mok MS, Lee C. Ketamine potentiates pancuronium-induced neuromuscular block. Anesth Aralg 1987; 66: $\$ 179$.

12 Abdul-Rasool $1 H$, Sears $D H$, Katz RL. The effect of a second dose of succinylcholine on cardiac rate and rhythm following induction of anesthesia with etomidate or midazolam. Anesthesiology 1987; 67: 795-7.

13 Muir AW, Marshall RJ. Comparative neuromuscular blocking effects of vecuronium, pancuronium, Org- 6368 and suxamethonium in the anaesthetized domestic pig. Br J Anaesth 1987; 59: 622-9.

14 Savarese JJ, Ali HH, Murphy JD, Padget C, Lee C, Ponitz $J$. Train-of-four nerve stimulation in the management of prolonged neuromuscular blockade following succinylcholine. Anesthesiology 1975; 42: 106-11.

\section{Résumé}

L'effet de linjection intraveineuse de kétamine 2, 5 et 10 $m g \cdot \mathrm{kg}^{-1}$ sur l'action de la succinylcholine a été étudié chez des singes anesthêsiés avec 0.5-1.0 pour cent d'halothane. Le changement du bloc neuromusculaire a été quantifié par des twitch simples évoqués à $0.1 \mathrm{~Hz}$. L'altération du bloc neuromusculaire de la Phase I à la Phase II a été surveillé périodiquement par l'observation du fade lors d'une ondés-de-quatre. En l'absence de succinylcholine, la kétamine He présentait aucun effet neuromusculaire. En présence de succinylcholine la kétamine selon la dose, a potentialisé l' effet neuromusculaire de la succinylcholine tant sur la Phase I que sur la Phase II. Dans la Phase I, $2 \mathrm{mg} \cdot \mathrm{kg}^{-1}$ de kétamine a réduit la $E D_{50}$ de la succinylcholine de $0.46 \pm 0.07 \mathrm{mg} \cdot \mathrm{kg}^{-1}$ a $0.33 \pm$ $0.06 \mathrm{mg} \cdot \mathrm{kg}^{-1}\{P<0.01\}$, et augmenta le $25-75$ pour cent d'index de récupération de $4.0 \pm 0.4 \mathrm{~min}$ à $5.3 \pm 0.1 \mathrm{~min}$. $\{P$ $<0.01)$. Dans la Phase II, la kétamine à une dose identique a approfondi le bloc neuromusculaire maintenu par la perfusion de succinylcholine de $48 \pm 3$ pour cent à $71 \pm 2$ pour cent $(P<$ $0.01)$. On onclut que la kétamine potentialise la Phase I et la Phase II du bloc neuromusculaire produit par la succinylcholine. 